\title{
Association of inflammation with endothelial dysfunction in pregnancy induced hypertensive women
}

\author{
J. Visalasree ${ }^{1}$, Phlips Abraham,** \\ ${ }^{1}$ Assistant Professor, ${ }^{2}$ Professor, Dept. of Biochemistry, ${ }^{1}$ Annapoorna Medical College and Hospital, Tamil Nadu, \\ ${ }^{2}$ Al-Azhar Medical College and Super Speciality Hospital, Thodupuzha, Kerala, India
}

*Corresponding Author:

Email: pphilips4848@yahoo.com

Received: $25^{\text {th }}$ September, 2017

Accepted: $22^{\text {nd }}$ February, 2018

\begin{abstract}
Introduction: Pregnancy induced hypertension is considered as the major cause of maternal and perinatal mortality. Even though occurrence of PIH is due to abnormal placentation, endothelial dysfunction (ED) plays a pivotal role in the genesis of the multisystem disorder that develops in pre eclampsia and eclampsia. Excessive inflammation might lead to ED. So, a study has been designed to analyse some inflammatory markers (TNF- $\alpha$, HsCRP, IL-6) and their association with endothelial dysfunction (NO) in PIH women.

Materials and Methods: Study group consisted of Normotensive pregnant women $(\mathrm{N})$ preclamptic women (PE) and eclamptic women (E) with 100 subjects in each group in the 3rd trimester of pregnancy. They were investigated for TNF- $\alpha$, IL-6, HsCRP \& NO. Statistical analysis was done using ANOVA

Results: When compared to controls TNF- $\alpha$, IL-6, HsCRP levels were found to be significantly high \& NO levels were significantly low in PE, E group. Eclamptic women showed a significantly high level of TNF- $\alpha$, and low levels of NO when compared to PE group.

Conclusion: Early careful monitoring of TNF- $\alpha$ along with NO might be helpful to predict the origination and advancement of the disease. It may help in emerging approaches for diagnosis and prevention of maternal and fetal complications.
\end{abstract}

Keywords: PIH- Pregnancy induced hypertension, TNF- $\alpha$ - Tumor necrosis factor-alpha, IL-6 - Interleukin-6, HsCRP-High sensitive C-reactive protein, NO- Nitric oxide.

\section{Introduction}

Pregnancy induced hypertension (PIH) is the second most common medical disorder seen during pregnancy. ${ }^{1}$ Preeclampsia (PE) is pregnancy related disorder characterized by hypertension and proteinuria that occurs after 20 weeks of gestation. ${ }^{2}$ Expectant mothers with hypertension are predisposed towards the development of potentially lethal complications. The causes of hypertension during pregnancy, particularly preeclampsia (PE), remain unknown. $\mathrm{PE}$ is a complication of pregnancy with significant morbidity and mortality for both mother and fetus. ${ }^{3}$ It effects 5$7 \%$ of pregnancies worldwide. It is a multi-organ disorder usually recognized by new onset of hypertension and proteinuria appearing in the 2 nd half of pregnancy. Eclampsia is classified as presence of seizures, non-attributable to other causes, in a women diagnosed with PE. ${ }^{4}$ Placenta plays a principal role in the pathogenesis of the disease. ${ }^{5}$ The abnormal cytotrophoblast differentiation is an early defect that may lead to reduced placental perfusion and ischemia. ${ }^{6}$ Reduced placental perfusion leads to widespread endothelial dysfunction ${ }^{7}$ and it is considered as a classic hallmark of preeclampsia ${ }^{8}$ which likely affects the cerebral endothelium as well leading to cerebral edema and seizures seen in eclampsia. ${ }^{9}$ The contribution of endothelial dysfunction can be viewed in a superior context as part of the inflammatory network. ${ }^{10}$
During pregnancy a generalized maternal inflammatory response exists. ${ }^{11}$ But, it has been hypothesized that systemic inflammation gets exaggerated in preeclampsia. ${ }^{11}$ Tumor necrosis- $\alpha$ (TNF$\alpha)$ is a pro-inflammatory cytokine with a pleiotropic effect on the immune system, tissue homeostasis, embryonic development and placentation. When released in large amounts, TNF- $\alpha$ induces enhanced activation and injury to the vascular endothelium. IL-6 (Interleukin-6) is a proinflammatory cytokine which is involved in immune activation, vascular wall function and modulation of TNF- $\alpha$ production. ${ }^{12} \mathrm{HsCRP}$ It is an acute phase reactant produced by the liver in response to pro inflammatory cytokines, especially..$^{13}$ Therefore a study has been designed to analyse some inflammatory markers (TNF- $\alpha$, HsCRP, IL-6) and their association with endothelial dysfunction (NO) in PIH women.

\section{Materials and Methods}

A cross sectional analytical study was conducted in the inpatient ward of the Department of Obstetrics and Gynecology, Annapoorana institute of medical sciences, Salem, Tamilnadu from August 2012 to April 2016. The study was approved by the Institutional Ethics Committee of AMC\&H and informed consent was obtained from all participants. PIH patients were defined according to the NHBPEP (National high blood pressure education programme) guidelines. ${ }^{14}$ 


\section{Patients and controls}

Hundred each normotensive pregnant women who served as control (Group1), PE (Group2) \& E (Group3) patients were selected. The mean SBP in 3 groups were recorded as $(116 \pm 5.45$ vs. $162.18 \pm 18.26$ vs. $170 \pm$ 15.52) $\mathrm{mm} \mathrm{Hg}$. The mean DBP in 3 groups were recorded as $(75 \pm 5.99$ vs. $107.5 \pm 11.35$ vs. $112.28 \pm$ 10.59) $\mathrm{mm} \mathrm{Hg}$. The urine albumin levels in 3 groups were measured as $(150.92 \pm 33.4$ vs. $436 \pm 96$ vs. $432 \pm$ 101) $\mathrm{mg} / \mathrm{d}$. Preeclampsia was defined as having a systolic blood pressure $140 \mathrm{~mm} \mathrm{Hg}$ or a diastolic blood pressure $90 \mathrm{~mm} \mathrm{Hg}$ with proteinuria $300 \mathrm{mg} / \mathrm{d}$. Sign and symptoms of PIH like swelling in the hands, face and feet, severe headaches, abdominal pain, reduced output of urine or no urine, blood in the urine, a change in reflexes, convulsion/seizures, coma, dizziness, excessive vomiting, nausea and rapid gain in weight were recorded. Eclamptic complications like cerebro vascular, cardio vascular, visual, pulmonary, renal, hepatic, haemostatic and obstetrical were also recorded. Individuals with past history of cardiac, renal, hepatic illness, diabetes, and hypertensions were excluded.

\section{Statistical Analysis}

The quantitative variables like Systolic Blood Pressure (SBP), Diastolic Blood Pressure (DBP), serum TNF- $\alpha$, IL-6, HsCRP, and NO were compared between PE, E women \& Normotensive controls. The same was also compared between PE \& E. The data was processed on computer software package SPSS version
20. The numerical data was presented as Mean \pm SD. A value of $\mathrm{P}<0.05$ at $95 \% \mathrm{CI}$ was considered as statistically significant.

\section{Results}

Table 1 shows base line characteristics like maternal age, gestational age, SBP, DBP, urine albumin between 3 groups. The SBP, DBP, urine albumin levels were significantly higher in $\mathrm{PE} \& \mathrm{E}$ women $(\mathrm{P}=0.000$, $\mathrm{P}=0.000, \mathrm{P}=0.000$ ) than controls and the levels were significantly high in eclamptic women compared to $\mathrm{PE}$ patients $(\mathrm{P}=0.001, \mathrm{P}=0.000, \mathrm{P}=0.000)$. The maternal age and gestational age was almost comparable between all the groups.

Table 2 shows mean TNF- $\alpha$, IL- 6 , HsCRP, and NO values between 3 groups. Preeclamptic and eclamptic patients showed a significantly higher serum TNF- $\alpha$, IL-6, HsCRP levels and significantly lower NO than controls $(\mathrm{P}=0.000, \mathrm{P}=0.000, \mathrm{P}=0.000, \mathrm{P}=0.000)$ and the TNF- $\alpha$ levels were significantly high $(\mathrm{P}=0.000)$ and NO levels were significantly low $(\mathrm{P}=0.000)$ in eclamptic women than preeclampsia whereas IL-6 \& HsCRP levels were not significant between PE \& E.

Table 3 shows the correlation analysis between inflammatory markers (TNF- $\alpha$, IL-6, HsCRP) and endothelial dysfunction (NO). The inflammatory markers were negatively correlated with Nitric oxide (NO).

Table 1: Comparison of baseline characteristics between the groups

\begin{tabular}{|c|c|c|c|c|c|c|c|c|c|}
\hline \multirow{2}{*}{ Parameters } & \multicolumn{2}{|c|}{ Controls } & \multicolumn{2}{|c|}{ Pre-eclampsia } & \multirow{2}{*}{$P$ value } & \multicolumn{2}{|c|}{ Eclampsia } & \multirow{2}{*}{$P$ value } & \multirow{2}{*}{$\begin{array}{l}\text { P-value } \\
\text { between } \\
\text { PE \& E }\end{array}$} \\
\hline & Mean & SD & Mean & SD & & Mean & SD & & \\
\hline Age (Years) & 23.97 & 3.30 & 24.62 & 4.07 & NS & 25.71 & 3.71 & $<0.01$ & NS \\
\hline $\begin{array}{l}\text { Gestational } \\
\text { Age (weeks) }\end{array}$ & 31.57 & 2.67 & 32.42 & 3.12 & NS & 31.05 & 2.90 & NS & NS \\
\hline SBP (mm Hg) & 116 & 5.45 & 162.18 & 18.26 & $<0.01$ & 170 & 15.52 & $<0.01$ & $<0.01$ \\
\hline DBP (mm Hg) & 75 & 5.99 & 107.5 & 11.35 & $<0.0 .1$ & 112.28 & 10.59 & $<0.05$ & $<0.01$ \\
\hline $\begin{array}{l}\text { Urine albumin } \\
\text { (mg/day) }\end{array}$ & 150.9 & 33.4 & 436 & 96 & $<0.01$ & 432 & 101 & $<0.01$ & $<0.01$ \\
\hline
\end{tabular}

*Data expressed as Mean \pm SD. A p value of $<0.05$ is considered as significant.

$* *$ Data expressed as Mean $\pm \mathrm{SD}$. A p value of $<0.01$ is considered as highly significant.

Table 2: Comparison of levels of inflammatory markers and NO between the groups

\begin{tabular}{|c|c|c|c|c|c|c|c|c|c|}
\hline \multirow{2}{*}{ Parameters } & \multicolumn{2}{|c|}{ Controls } & \multicolumn{2}{|c|}{ Pre-eclampsia } & \multirow{2}{*}{$P$ value } & \multicolumn{2}{|c|}{ Eclampsia } & \multirow[b]{2}{*}{$P$ value } & \multirow{2}{*}{$\begin{array}{l}\text { P-value } \\
\text { between } \\
\text { PE \& E }\end{array}$} \\
\hline & Mean & SD & Mean & SD & & Mean & SD & & \\
\hline TNF- $\alpha(\mathrm{pg} / \mathrm{ml})$ & 10.57 & 3.00 & 22.17 & 8.04 & $<0.01$ & 27.50 & 14.07 & $<0.01$ & $<0.01$ \\
\hline IL-6 (pg/ml) & 64 & 0.73 & 9.57 & 3.2 & $<0.01$ & 10.13 & 3.25 & 1 & NS \\
\hline HsCRP (mg/L) & 2.05 & 0.5 & 7.5 & 1.6 & 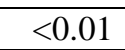 & 7.59 & 2.8 & 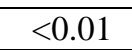 & NS \\
\hline NO $(\mu \mathrm{mol} / \mathrm{L})$ & 117.37 & 14.77 & 43.8 & 6.13 & $<0.01$ & 38.6 & 9.94 & $<0.01$ & $<0.01$ \\
\hline
\end{tabular}

$*$ Data expressed as Mean \pm SD. A p value of $<0.05$ is considered as significant.

$* *$ Data expressed as Mean $\pm \mathrm{SD}$. A p value of $<0.01$ is considered as highly significant. 
Graph 1: Levels of Inflammatory markers (TNF- $\alpha$, IL-6, HsCRP) among the groups

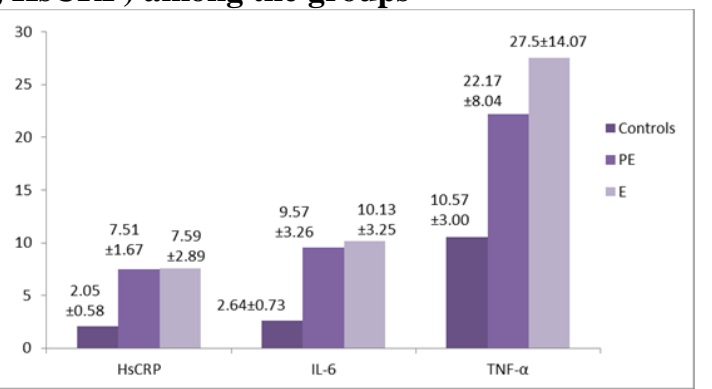

Graph 2: Nitric oxide levels among the groups

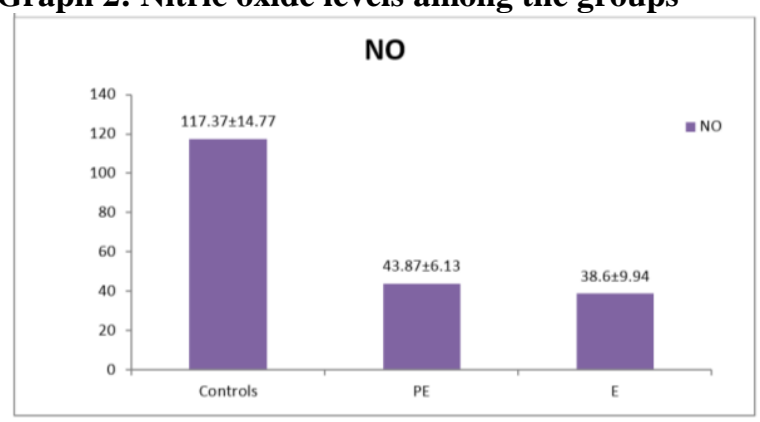

Table 3: Correlation analysis between inflammatory markers and endothelial dysfunction

\begin{tabular}{|l|c|}
\hline Parameter & $\begin{array}{l}\text { NO }(\boldsymbol{\mu m o l} / \mathbf{L}) \\
\text { 'r' value }\end{array}$ \\
\hline TNF- $\alpha(\mathrm{pg} / \mathrm{ml})$ & $-0.586^{* *}$ \\
\hline $\mathrm{IL}-6(\mathrm{pg} / \mathrm{ml})$ & $-0.766^{* *}$ \\
\hline $\mathrm{H} \mathrm{sCRP}(\mathrm{mg} / \mathrm{L})$ & $-0.760^{* *}$ \\
\hline
\end{tabular}

\section{Discussion}

Pregnancy-Induced Hypertension (PIH) remains to be a main obstetric problem in existing healthcare practice. It affects maternal health and also puts fetal development at risk. ${ }^{15}$ Normal pregnancy is characterized by a mild systemic inflammation, but the inflammation may become damaging if dysregulated. ${ }^{16}$ Increased inflammatory changes during pregnancy may be explained by different stimuli occurring at different phases of pregnancy such as implantation, monocyte/macrophage production stimulated by interleukin-6 (IL-6) and the necrotic process associated with placental ageing. ${ }^{17}$ Added to these reasons, in PE because of the placental hypo perfusion, ROS and cytokines are released from the placenta which may induce oxidative stress, inflammatory response and endothelial cell dysfunction in mother. ${ }^{18}$ An excessive inflammatory reaction has been associated with recurrent miscarriage or other pregnancy complications such as pre-eclampsia or premature labor ${ }^{19}$. In this respect our study displayed significant higher levels of TNF- $\alpha$, IL- 6 , HsCRP in PE \& E women compared to the normotensive pregnant women. But, only TNF- $\alpha$ levels were significantly higher in eclamptic women compared to pre-eclamptics whereas IL-6 \& HsCRP were not significant.

TNF- $\alpha$ and IL- 6 are some of the pro-inflammatory cytokines playing an important role in activation of immune system among pre-eclamptic women and are associated with disease severity. ${ }^{20}$ TNF-alpha is produced by monocytes, induces apoptosis, and inhibits proliferation of trophoblast cells in preeclampsia. ${ }^{21}$ Pathologically secreted TNF- $\alpha$ damage the vascular endothelial cells by causing occlusion of vessels there by reducing the regional blood flow leading to the increase in the permeability of endothelium. ${ }^{22}$ The displayed high levels of TNF - alpha in our study can be explained as a consequence of placental hypoxia which exists in PIH. ${ }^{23}$ The ROS generated by hypoxia /reoxygenation insults of placenta might also play a central role in placental expression and production of TNF-alpha by direct activation of p38 MAP kinase (mitogen activated kinase) and NF-KB (Nuclear factor). ${ }^{24}$ Furthermore, in preeclampsia the placenta derived factors might stimulate monocytes and neutrophils to produce TNF- $\alpha$ that lead to endothelial disturbances. ${ }^{25}$ Generally the monocytes are the main reservoir for proinflammatory cytokines and therefore can be good candidates for excessive TNF- $\alpha$ synthesis in preeclampsia. ${ }^{26}$

Unlike most cytokines, circulating TNF- $\alpha$ can cross the blood brain barrier (BBB) through receptormediated endocytosis. The binding of TNF- $\alpha$ to its receptors on the BBB upsurges paracellular permeability that can promote vasogenic edema. ${ }^{27}$ TNF- $\alpha$ up regulates endothelial cell adhesion molecules such as E-selectin, ICAM-1 and VCAM-1 that facilitate passage of leukocytes into the brain. Leukocyte infiltration of the BBB has been revealed to be seizure provoking by activating microglia that can then produce TNF- $\alpha$. In the brain, the production of TNF- $\alpha$ lower the seizure threshold and cause seizures ${ }^{28}$ by altering the balance of excitation AMPA ( $\alpha$-amino-3-hydroxy-5methyl-4-isoxazolepropionic acid receptor) and inhibition (GABAA ( $\gamma$-amino butyric acid receptor) receptors. ${ }^{28}$

Many reports indicated that the plasma of preeclamptic patients contain elevated levels of IL-6, a multifunctional cytokine that regulates hematopoiesis along with acute phase reaction. It controls both proand anti-inflammatory events. In the present study elevated IL-6 levels might be due to the characteristic decidual secretion. TNF-alpha, markedly up-regulates the IL-6 mRNA and its protein expression by the resident decidual cells. ${ }^{26}$

Moreover plasma from pre-eclamptic women activates vascular endothelial cells through an NF-кBmediated mechanism, these cells could be a potential source of increased circulating IL- 6 that is seen in this disease. ${ }^{29}$ Elevated IL-6 interferes with endothelial cell function by increasing the endothelial cell permeability by changing the cell shape and rearrangement of 
intracellular actin fibers. ${ }^{23}$ It increases the thromboxane A2 to prostacyclin ratio; reduce prostacyclin (PG I2) synthesis by inhibiting the cyclooxygenase enzyme and stimulating the platelet derived growth factor. It could also trigger the neutrophil activation, expression of von Willebrand factor and cell adhesion on the endothelium resulting in vascular damage. ${ }^{26}$ The inflammatory mediators TNF- $\alpha$, IL-8 and IL 1- $\beta$ synergizes with elevated plasma IL-6 levels to promote systemic vascular damage, particularly in the kidney, that results into a characteristic proteinuria and hypertension of the maternal syndrome of PE. ${ }^{30}$

$\mathrm{C}$-reactive protein (CRP) is an acute phase protein which is increased in systemic inflammation. During the challenges like severe tissue injury, microbial infections, systemic autoimmune disease and malignant tumors it is mainly synthesized by hepatocytes. Our results regarding HsCRP were in consistent with several studies. ${ }^{17,18}$ The reason might be due to the regulation of production by the correspondent gene located on the long arm of chromosome 1, induced at the transcriptional level by IL-6 \& tumor necrosis factor-alpha (TNF- $\alpha$ ). ${ }^{17,29}$ The cytokines exert their biological effects on CRP by signaling through their receptors on hepatic cells there by activating different kinases and phosphatases. This leads to the translocation of various transcription factors on the CRP gene promoter and the production of CRP. The concentration of CRP doubles for every 8 hours and peaks at 36-50 hours, while it depends on the stimulus and its severity. CRP concentration can increase above $500 \mathrm{mg} / \mathrm{l}$ and this amounts to as much as a 1000-fold or more concentration variation in response to a inflammatory insult. CRP, in agreement with its proposed function, may play a role in eliciting the inflammatory response characteristics of preeclampsia. ${ }^{31}$ However, the nonsignificant levels of IL-6 and HsCRP between PE \& E groups displayed in our study need to be evaluated further.

$\mathrm{NO}$ is an endothelium derived factor responsible for vasodilatation and platelet activation inhibition. It is involved in various stages of pregnancy including implantation, maintenance of uterine acquiescence during pregnancy, control of uterine contractions and relaxation, basic physiological adaption for successful gestation and regulation of blood pressure. ${ }^{32}$ The hallmark of ED is impaired NO bioavailability..$^{33}$ Our study displayed significantly low levels of NO in PE \& $\mathrm{E}$ women than in controls. The levels of NO were significantly low in eclamptic women than in preeclamptic women. Our results were in consistent with other studies. ${ }^{34,35}$ The inflammatory cytokines can also inhibit eNOS, causing reduction in NO levels leading to vasoconstriction in the peripheral circulation. ${ }^{36}$ It has also been stated that arginine deficiency can also reduce NO and increase superoxide formation, leading to NO degradation and excess peroxynitrite formation. ${ }^{37}$

\section{Conclusion}

Our results indicate that the women with $\mathrm{PE} \& \mathrm{E}$ exhibit markedly elevated concentrations of inflammatory cytokines (TNF- $\alpha$, IL-6, HsCRP). However the high levels of TNF- $\alpha$ among eclamptics than preeclamptics in our study indicate that TNF- $\alpha$ is a better marker for predicting the onset and progression of disease. Moreover, the negative correlation between inflammatory cytokines with $\mathrm{NO}$ indicates that the inflammation is directly related with the severity of ED in PIH women. So, early careful monitoring of TNF- $\alpha$ along with $\mathrm{NO}$ might help to predict the origination and advancement of the disease.

\section{References}

1. Parmar, M. T., Solanki, H. M., \& Gosalia, V. V. (2012). Study of risk factors of perinatal death in pregnancy induced hypertension (PIH). Natl J Community Med, 3(4),703-7.

2. Can, M., Sancar, E., Harma, M., Guven, B., Mungan, G., \& Acikgoz, S. (2011). Inflammatory markers in preeclamptic patients. Clinical chemistry and laboratory medicine, 49(9), 1469-72.

3. Makris, A., Thornton, C., Thompson, J., Thomson, S., Martin, R., Ogle, R., \& Hennessy, A. (2007).

Uteroplacental ischemia results in proteinuric hypertension and elevated sFLT-1. Kidney international, 71(10), $977-84$.

4. Bell, M. J. (2010). A historical overview of preeclampsiaeclampsia. Journal of Obstetric, Gynecologic, \& Neonatal Nursing,39(5),510-8.

5. Akhlaq, M., Nagi, A. H., \& Yousaf, A. W. (2012). Placental morphology in pre-eclampsia and eclampsia and the likely role of NK cells. Indian Journal of Pathology and Microbiology, 55(1),17.

6. Hladunewich, M., Karumanchi, S. A., \& Lafayette, R. (2007). Pathophysiology of the clinical manifestations of preeclampsia. Clinical Journal of the American Society of Nephrology, 2(3),543-9.

7. Gilbert, J. S., Nijland, M. J., \& Knoblich, P. (2008). Placental ischemia and cardiovascular dysfunction in preeclampsia and beyond: making the connections. Expert review of cardiovascular therapy, 6(10),1367-77.

8. Spracklen, C. N., Smith, C. J., Saftlas, A. F., Robinson, J. G., \& Ryckman, K. K. (2014). Maternal hyperlipidemia and the risk of preeclampsia: a meta-analysis. American journal of epidemiology,180(4),346-58.

9. Cipolla, M. J. (2007). Cerebrovascular function in pregnancy and eclampsia. Hypertension, 50(1),14-24.

10. Redman, C. W., \& Sargent, I. L. (2004, November). Preeclampsia and the systemic inflammatory response. In Seminars in nephrology (Vol. 24, No. 6, pp. 565-570). WB Saunders.

11. Redman, C. W., Sacks, G. P., \& Sargent, I. L. (1999). Preeclampsia: an excessive maternal inflammatory response to pregnancy. American journal of obstetrics and gynecology, 180(2),499-506.

12. Afshari, J. T., Ghomian, N., Shameli, A., Shakeri, M. T., Fahmidehkar, M. A., Mahajer, E., \& Emadzadeh, M. (2005). Determination of Interleukin-6 and Tumor Necrosis Factor-alpha concentrations in IranianKhorasanian patients with preeclampsia. BMC pregnancy and Childbirth, 5(1),14. 
13. Ali, Z., Zaki, S., Tauseef, A., \& Akmal, A. (2013). C Reactive Protein levels are elevated in the Third Trimester in Preeclamptic pregnant Women. Pakistan Journal of Medical and Health Sciences, 7(1).

14. Program, N. H. B. P. E. (2000). Report of the national high blood pressure education program working group on high blood pressure in pregnancy. American journal of obstetrics and gynecology, 183(1), s1-s22.

15. Packer, C. S. (2005). Biochemical markers and physiological parameters as indices for identifying patients at risk of developing pre-eclampsia. Journal of hypertension, 23(1), 45-6.

16. Ann-Charlotte, I. (2013). Inflammatory mechanisms in preeclampsia. Pregnancy Hypertension: An International Journal of Women's Cardiovascular Health, 3(2), 58.

17. Dhok, A. J., Daf, S., Mohod, K., \& Kumar, S. (2011). 'Role of Early Second Trimester High Sensitivity CReactive Protein for Prediction of Adverse Pregnancy Outcome'.

18. Catarino, C., Santos-Silva, A., Belo, L., Rocha-Pereira, P., Rocha, S., Patrício, B., \& Rebelo, I. (2012). Inflammatory disturbances in preeclampsia: relationship between maternal and umbilical cord blood. Journal of pregnancy, 2012.

19. Martínez-Varea, A., Pellicer, B., Perales-Marín, A., \& Pellicer, A. (2014). Relationship between maternal immunological response during pregnancy and onset of preeclampsia. Journal of immunology research, 2014.

20. Vitoratos, N., Economou, E., Iavazzo, C., Panoulis, K., \& Creatsas, G. (2010). Maternal serum levels of TNF-alpha and IL-6 long after delivery in preeclamptic and normotensive pregnant women. Mediators of inflammation, 2010.

21. Seki, H., Matuoka, K., Inooku, H., \& Takeda, S. (2007). TNF- $\alpha$ from monocyte of patients with pre-eclampsiainduced apoptosis in human trophoblast cell line. Journal of Obstetrics and Gynaecology Research, 33(4), 408-16.

22. Vahid Roudsari, F., Ayati, S., Ayatollahi, H., Esmaeily, H., Hasanzadeh, M., Shahabian, M., \& Pour Ali, L. (2009). Comparison of maternal serum Tumor Necrosis Factor-alpha (TNF- $\alpha$ ) in severe and mild preeclampsia versus normal pregnancy. International Journal of Reproductive BioMedicine, 7(4),153-8.

23. Conrad, K. P., \& Benyo, D. F. (1997). Placental cytokines and the pathogenesis of preeclampsia. American journal of reproductive immunology, 37(3), 240-9.

24. Hung, T. H., \& Burton, G. J. (2006). Hypoxia and reoxygenation: a possible mechanism for placental oxidative stress in preeclampsia. Taiwanese Journal of Obstetrics and Gynecology, 45(3),189-200.

25. Bakheet, M. S., Seddik, M. I., Abdelzaher, M. H., \& Abdelshakor, M. (2016). Evaluation of TNF- $\alpha$, Nitric Oxide, Lipid Profile, Urea and Creatinine Serum Levels for the Prediction of Preeclampsia. International Journal, 27.

26. Lockwood, C. J., Yen, C. F., Basar, M., Kayisli, U. A., Martel, M., Buhimschi, I., ... \& Schatz, F. (2008). Preeclampsia-related inflammatory cytokines regulate interleukin-6 expression in human decidual cells. The American journal of pathology, 172(6), 1571-9.

27. Pan, W., Csernus, B., \& Kastin, A. J. (2003). Upregulation of $\mathrm{p} 55$ and $\mathrm{p} 75$ receptors mediating TNF- $\alpha$ transport across the injured blood-spinal cord barrier. Journal of Molecular Neuroscience, 21(2), 173-84.

28. Cipolla, M. J., \& Kraig, R. P. (2011). Seizures in women with preeclampsia: mechanisms and management. Fetal and maternal medicine review, 22(2), 91-108.

29. Swellam, M., Samy, N., Abdl Wahab, S., \& Ibrahim, M. S. (2009). Emerging role of endothelial and inflammatory markers in preeclampsia. Disease markers, 26(3), 127-33.

30. Lockwood, C. J., Yen, C. F., Basar, M., Kayisli, U. A., Martel, M., Buhimschi, I., \& Schatz, F. (2008). Preeclampsia-related inflammatory cytokines regulate interleukin-6 expression in human decidual cells. The American journal of pathology, 172(6), 1571-9.

31. Mandal, K. K., Das, A., Devi, H. L., Omita, N., Singh, N. N., \& Singh, W. G. "Serum high sensitivity C-reactive Protein as predictor of Preeclampsia". IOSR Journal of Dental and Medical Sciences (IOSR-JDMS), 1(15), 2631.

32. Saha, T., Halder, M., Das, A., \& Das, S. K. (2013). Role of nitric oxide, angiogenic growth factors and biochemical analysis in preeclampsia.

33. Sena, C. M., Pereira, A. M., \& Seiça, R. (2013). Endothelial dysfunction - a major mediator of diabetic vascular disease. Biochimica et Biophysica Acta (BBA)Molecular Basis of Disease, 1832(12), 2216-31.

34. Seligman, S. P., Buyon, J. P., Clancy, R. M., Young, B. K., \& Abramson, S. B. (1994). The role of nitric oxide in the pathogenesis of preeclampsia. American journal of obstetrics and gynecology, 171(4), 944-8.

35. Sandrim, V. C., Palei, A. C., Metzger, I. F., Gomes, V. A., Cavalli, R. C., \& Tanus-Santos, J. E. (2008). Nitric oxide formation is inversely related to serum levels of antiangiogenic factors soluble fms-like tyrosine kinase-1 and soluble endogline in preeclampsia. Hypertension, 52(2), 402-7.

36. Matsubara, K., Higaki, T., Matsubara, Y., \& Nawa, A. (2015). Nitric oxide and reactive oxygen species in the pathogenesis of preeclampsia. International journal of molecular sciences, 16(3), 4600-14.

Huang, L. T., Hsieh, C. S., Chang, K. A., \& Tain, Y. L. (2012). Roles of nitric oxide and asymmetric dimethylarginine in pregnancy and fetal programming. International journal of molecular sciences, 13(11), 14606-22. 